\title{
Explicating the dynamics of project capabilities
}

\author{
Andrew Davies \\ University College London \\ The Bartlett Faculty of the Built Environment \\ 1-19 Torrington Place \\ London WC1E 7HB \\ Tel: +44 (0)2031083073 \\ e-mail: a.c.davies@ucl.ac.uk
}

\author{
Tim Brady \\ CENTRIM \\ University of Brighton \\ $154-155$ Edward Street \\ Brighton BN2 0JG UK \\ Tel: +44 7903843759 \\ e-mail: t.m.brady@brighton.ac.uk
}

Key words: project capabilities; dynamic and operational capabilities; ambidexterity

\begin{abstract}
:
This article provides a foundation to guide future research on project capabilities by providing three main contributions. First, drawing upon research on dynamic capabilities and organisational ambidexterity, we suggest that innovative and routine dimensions of project capabilities are developed and mobilised to deal with the variety of exploratory and exploitative conditions facing an organisation. Second, we distinguish between project capabilities at the operational and dynamic capabilities at the strategic levels, arguing that firms depend on identifiable dynamic capabilities (e.g. portfolio management techniques) to know when and how to maintain current project capabilities and when to modify or replace them depending the conditions encountered. Third, we suggest that the relationship between dynamic and project capabilities is reciprocal, recursive and mutually reinforcing. In this reciprocal relationship, the emergence of new or declining project capabilities provide indications for the strategic priorities, behaviours and future deployment of an organisation's dynamic capabilities.
\end{abstract}




\section{Introduction}

One of Peter Morris's many contributions to the project management literature is to underline the role of people, knowledge and experience in the successful management of projects (Morris and Hough, 1987; Morris, 1994 and 2013). Organisations face the challenge of finding people with the right knowledge and skills for each project, whilst maintaining the collective knowledge, skills and resources required to manage adjacent and subsequent projects and programs. The Anatomy of Major Projects (1987) drew attention to the exceptional level of managerial experience required to cope with large, complex, urgent, innovative and uncertain projects and recognized that the knowledge and expertise embodied in individuals and project teams, which is so crucial to management of these projects, tends to become lost when the project is disbanded. The Management of Projects (1994) identified how competencies - or general skill and knowledge base of individuals and teams contribute to the successful management of projects, stressing the formal project management education and training of individuals, rather than project- and firm-specific competencies. Reconstructing Project Management (2013) acknowledges the difference between the competencies that an individual needs to perform a role in a project and the capabilities organisations develop and maintain to manage multiple projects and programs.

The professional skills that individuals need to manage a project or program are identified in the generic competency frameworks and Bodies of Knowledge developed by institutions such as the Project Management Institute and Association of Project Management. But, as Morris (2013) recognizes, capabilities defined at the organisational level need to be tailored to the requirements of specific firms and projects. The authors of this paper attempted to address this issue by introducing the notion of 'project capabilities' (Davies and Brady, 2000; Brady and Davies, 2004; Davies and Hobday, 2005). The concept refers to the distinctive managerial knowledge, experience and skills, which are located within a single organisation (a firm) and required to establish, coordinate and execute projects.

As it is now over a decade since our original work was published, the purpose of this article is to revisit, reformulate and extend the concept of project capabilities proposed by the 
authors and developed further by other scholars (e.g. Grabher, 2002; Killen, Jugdev, Drouin and Petit, 2008; Shamsie, Martin and Miller, 2009; Söderlund and Tell, 2009; Cattini, Ferriani, Frederiksen and Täube, 2011; Nightingale, Baden-Fuller and Hopkins, 2011; Grabher and Thiel, 2015). We provide a new conceptualisation of project capabilities that addresses recent theoretical debates, new empirical research, and applies to a wider variety of project-based domains than our original formulation.

This article provides a foundation to guide future research on project capabilities by providing three main contributions. First, drawing upon research on dynamic capabilities and organisational ambidexterity (Teece, Pisano and Shuen, 1997; Tushman and O'Reilly, 2008), we suggest that project capabilities are developed and mobilised to deal with the variety of contingent conditions facing an organisation (Eisenhardt and Martin, 2000). They are used to explore innovative new possibilities and deal with rapidly changing and uncertain conditions, whilst at the same time used to exploit current routines and perform repetitive processes when conditions are stable and repetitive. Second, informed by the dual-routines view of organisational capabilities (Nelson and Winter, 1982; Chandler, 1992; Zollo and Wiinter, 2002; Helfat and Peterat, 2003), we distinguish between project capabilities at the operational and dynamic capabilities at the strategic levels of an organisation. Firms depend on identifiable dynamic capabilities (e.g. portfolio management techniques) to know when and how to maintain current project capabilities and when to modify or replace them depending the conditions encountered. Third, whereas prior studies assume that operational capabilities are changed and altered solely by the top-down action of dynamic capabilities, we suggest that the relationship between dynamic and project capabilities is reciprocal, recursive and mutually reinforcing. In this reciprocal relationship, the emergence of new project capabilities at the frontier of innovation or the gradual demise of mature project capabilities in declining markets provide strong bottom-up indications for the strategic priorities, behaviours and future deployment of an organisation's dynamic capabilities.

The article is divided into the following sections. Section 2 discusses the origins, purpose and various theoretical perspectives informing the concept of project capabilities. 
Section 3 provides a review of the main contributions to dynamic capabilities research, much of it published since our original work on project capabilities. Section 4 suggests that the concept should be reformulated to address theoretical advances in research on dynamic capabilities and organisational ambidexterity, arguing that dynamic and project capabilities are required to explore innovative opportunities in new and rapidly evolving technologies and markets, whilst exploiting the current capabilities required to maintain and extend existing activities. Section 5 identifies promising directions for future research on how project capabilities are assembled, deployed and maintained.

\section{Origins, nature and scope of project capabilities}

The concept of project capabilities was originally devised to understand how projectbased firms in the late 1990s moved strategically into the provision of innovative bundles of products and services for their customers (Davies and Brady, 2000; Davies, 2005; Davies, Brady and Hobday, 2006). Ericsson's turnkey project for a large mobile communications operator represented the beginning of its move from being a manufacturer of mobile communications equipment to becoming a systems integrator and service provider. Cable $\&$ Wireless's global outsourcing project for a large international bank marked the start of its move from the provision of managed corporate networks within different national markets to a provider of global outsourcing solutions, providing multinational corporate customers with fully-integrated networks, systems and services from a single source. Each firm's shift into the new markets was initiated by a highly innovative and unique first-of-its kind project. Both firms provided repeatable solutions in the new line of business by recycling the learning from one project to the next. They obtained 'economies of repetition' by establishing the standardised project routines required to execute a growing number of bids and projects at lower cost and more effectively.

In its original formulation, project capabilities described the knowledge, tasks and structures that firms require to design and produce complex products and systems as one-offs units or in small tailored batches to address the requirements of large business, government and institutional clients. Project capabilities refer to the activities and structures required to 
manage the project through its life from the front-end engagement with clients and sponsors, through tendering and project delivery, to the back-end hand-over to the customer and provision of on-going support (Davies and Brady, 2000). These are core activities for firms whose business involves delivering projects for external customers but similar capabilities are needed by all firms for their internal projects.

Written when research on dynamic capabilities was still in its infancy, our concept drew upon several different knowledge-based theories of the firm perspectives including the resource-based view of the firm (Penrose, 1959), organisational capabilities (Richardson, 1972; Nelson and Winter, 1982; Chandler, 1990) and dynamic capabilities (Teece and Pisano, 1994; Teece, Pisano, and Shuen, 1997). Evolutionary theory emphasises the importance of firm-specific organisational capabilities and routines as a source of stability and innovation (Nelson and Winter, 1982) and RBV research helped us identify how a firm's distinctive knowledge base provides the internal dynamic behind firm growth and diversification into new technologies and markets (Penrose, 1959; Wernerfelt, 1984; Barney 1991). Research on dynamic capabilities helped us understand how firms rely on strategic routines to integrate, configure, build and recombine internal and external competencies to keep pace with a rapidly changing technology and market environment (Teece and Pisano, 1994; Teece, Pisano and Shuen, 1997).

Whilst these ideas helped to frame our study, we suggested that Chandler's (1990) argument that organisational capabilities are the knowledge-acquiring process and dynamic behind the growth of the modern firm should be modified to include projects. Organisational capabilities are the firm-specific knowledge and skills developed by learning through trial and error, feedback and evaluation. Chandler identified two levels of capability in the 'managerial hierarchy' of the firm. Strategic capabilities refer to top management skills and learned routines needed to support strategic planning, coordinate functional activities and diversification decisions. Functional capabilities refer to the day-to-day operations performed by a firm's functional departments including production, distribution, purchasing, research, finance and general management. Firms gain competitive in existing technologies and 
markets by developing the functional capabilities to move down the learning curve in each of a firm's functional activities more rapidly than competitors and by obtaining economies of scale and scope by moving rapidly from low to high-volume production, distribution and marketing. Strategic capabilities provide a more powerful source of competitive advantage by responding to moves by competitors, moving rapidly into new technologies and markets, and adapting to a constantly changing environment.

Although Chandler's capabilities framework identifies how firms evolve through the product life cycle to high-volume stages of production, we argued that it neglects to identify the specific capabilities required to produce complex, high-value capital goods and services such as gas turbines, oil and gas platforms and flight simulators. These project-based firms seldom if ever, evolve to a stage of highly standardised, high-volume production (Hobday, 1998; Davies and Hobday, 2005). We therefore introduced the concept of project capabilities to identify the distinctive knowledge required to undertake unit and small batch production in projects that are tailored to individual customer requirements. Located alongside functional capabilities, project capabilities are similar to what scholars now call operational capabilities (Helfat and Peteraf, 2003). Strategic capabilities are located centrally in the corporate organisation and distributed within operating business units, project and functional organisations. They perform a similar role to dynamic capabilities (Teece et al, 1997; Teece, 2010). Whereas strategic capabilities are relied upon to guide investment decisions, the allocation of resources and the future direction of the firm, different combinations of functional and project capabilities, organised in various types of project or matrix structures, enable firms to improve existing products and processes, and develop new ones.

We extended our prior work by locating in the process of project capability building within the theoretical frame of organisational learning (Brady and Davies, 2004). Drawing upon March (1991), we argued that an initial move into a new base of projects is initiated by bottom-up, exploratory learning when a firm explores the creative new ideas and innovative combinations of resources and capabilities brought together in a 'vanguard project'. For the sake of simplicity and conceptual clarity, we now suggest that vanguard projects include the 
idea of 'venture projects' formed internally to support entrepreneurial efforts to create new customers and markets (Frederiksen and Davies, 2009). Core project capabilities aligned to a firm's previous base can become 'core rigidities' (Leonard-Barton, 1992) holding back efforts to explore new ideas and approaches when a firm moves base. Over time, the emphasis switches to top-down, exploitative learning as the firm uses the learning gained strategically to develop the firm-wide capabilities, resources and routines required to support a growing number of the new category of project.

We attempted to build a stronger theoretical foundation - and a wider application for the concept of project capabilities by going back to Penrose (1959) and subsequent RBV and dynamic capabilities research (Brady and Davies, 2004; Davies and Hobday, 2005). Whereas a firm's existing project capabilities are built around its existing technology market base, a firm's new and emerging project capabilities are associated with base-moving strategies. Projects are a vehicle for implementing a firm's strategy for innovation and diversification. They create novel combinations of capabilities and resources required to expand into a new business base using new technology to address the requirements of new customers or create new markets, to diversify into a new market base using existing technology, and to move into a new technology base to supply new products and services to existing customers.

Several other studies have recognized the importance of project-related competencies and capabilities, including the project management competencies of individual managers (Morris, 1994 and 2013; Söderlund, 2005), the project execution capabilities in developing countries (Amsden and Hikino, 1994) and multi-project management capabilities for new product development (Cusumano and Nobeoka, 1998). Unlike this work, the concept of project capabilities identifies the core knowledge that an entire category of project-based firms require to compete, grow and innovate over the long term, emphasising how learning embedded in stable routines and capabilities shapes future action and provides a source of valuable knowledge when applied repeatedly across multiple projects (Gann and Salter, 2000; Hobday, 2000; Prencipe and Tell, 2001; Whitley, 2006). 
In the next two sections, we consider how the concept can be reformulated and extended to address recent developments in theories of dynamic capabilities.

\section{Theoretical foundations: revisiting dynamic capabilities}

Dynamic capabilities refer to identifiable management and organisational processes required to implementation strategies, create innovation and adapt to an evolving environment. Although applicable to firms in a very wide variety of settings, with a few notable exceptions (Ethiraj, Kale, Krishnan and Singh, 2005; Shamsie et al, 2009) research on dynamic capabilities rarely addresses project-based organisations, firms and industries.

The concept of dynamic capabilities is associated with two main theoretical traditions: the resource-based view (RBV) of the firm and evolutionary theory (EasterbySmith, Lyles and Peteraf, 2009; Peteraf, Di Stefano and Verona, 2013; Di Stefano, Peteraf, and Verona, 2014). Scholars from both perspectives cross reference each other's work and emphasize that capabilities are previously learned patterns of action embodied in regular, predictable and repetitive routines. RBV and evolutionary research recognize that routines are the 'building blocks' of organizational capability (Winter, 1995; 148) and that ad hoc problem solving in response to novel or unpredictable events does not constitute a capability (Winter, 2003). As Helfat and Peteraf (2003: 999) clarify, an organisation has capability when it has achieved a threshold level of routine activity that permits the 'repeated, reliable performance of an activity'. More recent research recognises the importance of balancing exploratory and exploitative activities over time to keep pace with a range of environmental conditions, stable and rapidly changing (Eisenhardt, Furr and Bingham, 2010).

\subsection{The resource-based view}

The majority of research on dynamic capabilities is grounded in an RBV perspective and falls into two streams of literature (Peteraf et al, 2013). The first stream, associated with Teece and Pisano (1994) and Teece et al (1997) and its focus on technology, firm performance and strategy, aimed to identify how the RBV approach to strategy could be extended to deal with a dynamically changing environment. Dynamic capabilities enable top management to purposefully combine - adapt, integrate and reconfigure - internal and 
external resources in novel ways to deal with rapidly evolving technology, market and regulatory environments. In his later work, Teece (2007 and 2010) maintains that dynamic capabilities include the cognitive ability that senior managers need to sense and seize opportunities to reconfigure operating capabilities, assets and resources depending on the conditions encountered.

The second stream associated with Eisenhardt and Martin (2000) adds a contingency approach to RBV research on dynamic capabilities. Concerned with identifying different forms of organisational design, Eisenhardt and Martin (2000) identify two types of dynamic capabilities, depending on the degree of uncertainty in the market. In 'moderately dynamic markets', where change is frequent but along largely predictable incremental paths, dynamic capabilities resemble standard operating procedures (Cyert and March, 1963). These 'complex routines' are based on tacit knowledge and experience built over years and required to address recurring and predictable problems (Eisenhardt and Martin, 2000). In 'highvelocity markets', dynamic capabilities have to address unforeseeable environmental demands and master rapidly shifting conditions and rules. These 'simple routines' are based on structural principles and rules and relied upon to create new situation-specific knowledge, real-time experiential learning and improvisation (Eisenhardt and Martin, 2000; Eisenhardt and Sull, 2001; Danneels, 2008 and 2010).

\subsection{Evolutionary theory}

Evolutionary theory emphasises how dynamic capabilities depend on learning and adaptation in a changing environment (Zollo and Winter, 2002; Helfat and Peteraf, 2003). Building on Nelson and Winter (1982), the so-called 'dual-routines' framework suggests that dynamic capabilities are conceived as 'higher-order' routines located at a strategic level in the firm (Zollo and Winter, 2002; Helfat and Peteraf, 2003; Winter, 2003). In this dual-level hierarchy of organisational capabilities, firms rely on the dynamic capabilities of senior management to create innovation by modifying, recombining and creating new lower-order operating capabilities (Collis, 1994; Coriat, 2000; Zollo and Winter, 2002; Helfat and Peteraf, 2003; Winter, 2003; Helfat and Winter, 2011). Performing a role similar to standard operating 
procedures (Cyert and March, 1963), operational capabilities are relied upon to coordinate and perform a firm's productive activities. They provide stability and direction for tasks that are constantly recurring and minimize the need to predict uncertain future events.

Some evolutionary scholars suggest that dynamic capabilities depend on specific cognitive processes called 'metaroutines' to identify, challenge and modify lower-order routines that are no longer achieving desired performance targets (Amburgey, Kelly, and Barnett, 1993; Adler, Goldoftas, and Levine, 1999; Knott 2001, King and Tucci 2002; Wezel, Cattani, and Pennings, 2006). Exercising a metaroutine involves time for reflection, learning from feedback and managerial discretion to know when to modify routines to keep pace with changing environment and when to enforce them when conditions are stable and predictable (Wezel et al., 2006). For example, Total Quality Management and Toyota's lean production techniques are examples of metaroutines used to strike a balance between maintaining existing routines and encouraging innovation when conditions change (Hackman and Wageman, 1990; Adler et al., 1999).

Evolutionary research has identified that experiential and cognitive learning processes are involved in assessing whether operational routines are appropriate in a changing environment and whether there is a need to modify or replace them (Gavetti and Levinthal, 2000; Tripsas and Gavetti, 2000). Whereas experiential learning is conducted 'on-line' by assessing the performance of alternative practices, experiences and adjustments to existing routines, a cognitive search involves 'off-line' evaluations, consultations and experiments without actually implementing new practices or changing routines.

\subsection{Organisational ambidexterity}

Developing this idea that dynamic capabilities play a balancing role in responding to variation in the environment, O'Reilly and Tushman (2008) argue that organisational ambidexterity, or the ability of a firm to simultaneously explore and exploit, is a form of dynamic capability. Ambidexterity depends on the dynamic capabilities to exploit a firm's current routines, whilst exploring new opportunities that will define the future. This process is purposefully undertaken by senior managers to deal with the trade-offs involved in the 
'temporal sequencing' and 'simultaneous balancing' of exploration and exploitation (O'Reilly and Tushman, 2008).

Temporal sequencing is about managing the transition from one internally consistent structure and alignment to another. Firms rely on dynamic capabilities to know how and when to adjust their structures and capabilities. For example, to address different phases of the product life cycle, firms create organic, flat and adaptive projects to deal with a fluid and exploratory phase of high product innovation and move towards mechanistic structures when exploitation of a firm's current capabilities is required to grow in a mature technology and market environment (Utterback, 1994). This approach works well when the rate of change in the technology and market environment 'proceeds at a pace that permits firms to choose organisational alignments sequentially' (O'Reilly and Tushman, 2008: 193).

The dynamic capabilities required to pursue exploration and exploitation sequentially are quite different than when the two activities are pursued at the same time (Tushman and O'Reilly, 1996, 1997; O'Reilly and Tushman, 2004 \& 2008). Temporal sequencing is possibly less challenging than simultaneous balancing, because the rate of change in technologies and markets proceeds at a pace that allows firms to install organisational alignments and build project capabilities sequentially. Organisations establish dual structures with distinct, autonomous and internally consistent processes, cultures and incentives to deal with exploration and exploitation. For example, organic, adaptive and flat project-based organisations are ideally suited for rapidly changing and uncertain conditions, whereas mechanistic, vertical and hierarchical management organisations work well in stable and predictable environments (Burns and Stalker, 1961). The two separate structural units are held together by a 'common strategic intent, an overarching set of values, and target structural linking mechanisms to leverage shared assets' (O’Reilly and Tushman, 2008: 193).

In their research on innovation in projects, O'Reilly and Tushman (2004 and 2008) argue that firms that develop the dynamic capabilities required to mobilise for organisational ambidexterity are able to achieve breakthrough innovations that alter the basis of competition, develop new technologies or create new markets beyond the existing customer base, whilst 
making incremental improvements in their existing technologies and markets. Firms separate new exploratory units for breakthrough innovations from their traditional exploitative units to create appropriate structures, processes and cultures that are aligned to the two different sets of activities. They organise their breakthrough projects in four different ways: projects carried out within current functional designs; cross-functional project teams; unsupported teams; and ambidextrous organisations where breakthrough projects are organised as structurally independent units, with their own structure, processes, and culture, but integrated into an existing management hierarchy.

\section{A new conceptualisation of project capabilities}

Anchored in more recent theoretical advances in dynamic capabilities research, this section provides a new conceptualisation of project capabilities showing how they support a firm's routine and innovative projects and identifies the links between project capabilities at the operational level and dynamic capabilities at the strategic level of the firm.

\subsection{Project capabilities: routine and innovative}

Consistent with the evolutionary perspective (Winter, 1995), we suggest that individual routines are the building blocks of project capabilities. Project capabilities consist of a collection of routines and can be defined (alongside functional capabilities) as a subset of operational capabilities. Applying Nelson and Winter's (1982) evolutionary theory to project organisations, Stinchcombe and Heimer (1985: 248-249) identified 'project routines' as the central source of efficiency in projects, such as bidding, planning, scheduling, establishing the project organisation, forming teams, change control, and programme management. When people join a project much of their work is learning the routines of the project. A key challenge is ensuring that the reliable and predictable performance provided by project routines as they improve over time does not disappear when the project is dismantled. This is resolved by embodying project routines in standardized processes, codified guidebooks and artefacts that are made available for future projects.

A project can be defined as a temporary organisation, management process and sequence of tasks established to create a unique or customised product or service. Whilst 
every project is unique in some respect, all projects involve some degree of repetition. Lundin and Söderholm (1995) suggest that the tasks performed by a project organisation can be unique or repetitive. A project organisation focused primarily on performing unique tasks is created for a one-time situation that will not occur again in the future, whereas one focused primarily on repetitive tasks is devoted to a situation that will be repeated in the future. As Lundin and Söderholm (1995) clarify:

When a temporary organisation is assigned to a repetitive task, the actors know what to do, and why and by whom it should be done. Their experiences are similar and they share a common interpretation of the situation. However, when a task is unique, nobody has immediate knowledge about how to act. Visionary, flexible, and creative actions are consequently needed in addition to a more deliberate search for experiences from other areas.

To understand the difference between unique and repetitive endeavours, it is important to place projects in their wider historical context:

If we expand the timeframe, we find some projects really are unique undertakings, representing a completely new experience for the parent organisation. However, we also find that a large number the project assignments are of a repetitive nature, with little deviation in relation to preceding projects within the organisation (Engwall, 2003:793)

Building on this idea, our early research showed how firms transition from unique to repetitive projects over by first establishing a vanguard project and then gradually developing the routines required to achieve economies of repetition in the new category of project (Davies and Brady, 2000; Brady and Davies, 2004).

The distinction between unique and repetitive projects is addressed in research that identifies that the structures, processes and cultures of project management have to be adapted to the different requirements of exploration and exploitation (Eisenhardt and Martin, 2000; Pich, Loch and De Meyer, 2002; Loch, De Meyer and Pich, 2006; Lenfle, 2008). Eisenhardt and Tabrizi (1995) identify two models of project management: a 'compression model' based on rational, predictable and sequential process with predictable outcomes and an 'experiential model' that relies on improvisation, flexibility and real-time learning required to deal with uncertainty. Shenhar and Dvir (2007) distinguish between 'strategic projects' that maintain or 
enhance a firm's competitive position by creating new markets or new categories of products and 'operational projects' that enable a firm to maintain its current markets and existing business by improving and extending existing products, services and processes. Loch et al (2006) identify 'novel projects' organised to deal with unforeseen uncertainties and 'simple projects' that address predictable and repetitive tasks.

We recognise that our own research has used a variety of different and sometimes confusing terms to classify projects (first-of-their-kind v repetitive, vanguard v established, base-moving $\mathrm{v}$ base projects). To provide greater clarity and connect our work to mainstream theoretical work on dynamic capabilities and ambidexterity we identify two types of project: (1) 'routine projects' which exploit the existing base, utilise proven technologies and mature products, and address current customer demands; (2) 'innovative projects' which support base-moving strategies that explore innovative alternatives, experiment with new ideas, schemes and approaches, create entirely new technologies and markets.

Routine projects are focused on exploitation and organised to achieve predefined goals with a given set of resource constraints (time, cost and quality). They rely on traditional forms of project management based on compressed sequencing tasks and pre-specified instructions to achieve the reliability and predictability associated with economies of repetition. Innovative projects are focused on exploration, organised to deal with highly unforeseeable conditions when the means to achieve the objective is too difficult to define at the outset. Involving high degrees of novelty and complexity, innovative projects are difficult to plan in advance; 'complexity means that even if events could be foreseen, the interaction of events is so complex that contingency plans would be impossible to draw up' (Loch et al, 2006). Such exploration requires a fundamental shift in organisational design and a break with prior project routines and capabilities. It requires the establishment of a vanguard project to investigate the new opportunities, encourage creative problem solving and efforts to establish new project routines. This involves experiential search processes, real-time learning and the pursuit of multiple solutions until the best one can be selected (Klein and Meckling, 1958; Lenfle, 2008; Nightingale and Brady 2011). 


\subsection{The links between project and dynamic capabilities}

We have argued that a firm's reliance on innovative and routine projects is contingent on the rate of change and uncertainty in the technology, market and regulatory environment. What remains unclear is how the firm decides how to allocate its resources and manage the trade-offs between innovative and routine project capabilities. Following the theoretical guidance provided by the dual-routines perspective, we suggest that dynamic capabilities at the strategic level of the firm decide how to create and mobilise project capabilities to support ambidexterity. Senior managers rely on the cumulative knowledge and identifiable strategic processes associated with dynamic capabilities (e.g. strategic planning and portfolio management techniques) to know when to exploit routine project capabilities in an organisation's existing resource base under relatively stable and predictable conditions. At the same time, they have to decide how and when to launch innovative projects to keep pace with a changing environment or gain competitive advantage by creating new technologies, products and services.

Our new conceptualisation challenges the widely held view that dynamic capabilities act top-down on project capabilities in a unidirectional relationship. This perspective is consistent with Chandler's (1992) view that top management rely on strategic capabilities to coordinate and decide what is done at lower levels in the hierarchy. In contrast to most prior literature, we argue that the relationship between dynamic capabilities and project capabilities is reciprocal, recursive and mutually reinforcing. Dynamic capabilities ensure that project capabilities maintain a close fit with variation in the environment, but new capabilities often emerge, develop and form in vanguard projects at the frontier of innovation where new situation-specific knowledge, emerging rules and structural principles challenge existing routines and practices. Rather than relying on the intervention of dynamic capabilities to guide their actions, such projects often provide strategic focus, emerging insights and valuable signposts for the future direction of a firm. What goes on inside these innovative projects provides strong indications about how dynamic capabilities have to be reshaped to 
deal with novel and volatile changes in technologies and markets. Figure 1 illustrates the learning, reflection and feedback loops between dynamic and project capabilities.

insert Figure 1

Our new conceptualisation of project capabilities, and their links to dynamic capabilities, applies to project-based firms that rely on projects to conduct the majority of their productive activities for clients (Gann and Salter, 2000; Hobday, 2000; Whitley, 2006) and project-supported organizations (Lundin, Ardvisson, Brady, Ekstedt, Midler and Sydow, 2015) such as firms involved in high-volume standardised production that rely on projects to support strategic initiatives, organisational change and new product development activities (Davies and Frederiksen, 2010).

\subsection{Managing project capabilities}

Although studies of ambidexterity in the project management literature do not explicitly engage with the concept of dynamics capabilities (Pellegrinelli, Murray-Webster and Turner, 2014; Turner, Maylor and Swart, 2014; Turner, Maylor, Lee-Kelley, Brady, Kutsch and Carver, 2014), undertaking research on exploration and exploitation promises to enhance our understanding of how dynamic capabilities support more flexible forms of project-based organising. In particular, research on both dynamic and project capabilities may be helpful in providing a theoretical lens to improve our understanding of how firms implement strategies and learn through projects.

In this context, it is pertinent to distinguish between project, program and portfolio management. Whereas project management is about managing a project and product through its life cycle, program management is about the management of a collective set of interdependent projects with shared goals and resources (Morris, 2013). Some authors call for more research on program management as a dynamic capability used strategically by firms to achieve 'fitness' in an evolving environment (Pellegrinelli, Partington and Geraldi, 2012: 264). However, we suggest that both project and program management are part of an 
organisation's project capabilities at the operational level. They are not only deployed to develop and improve existing products and processes, but also to support strategies for innovation and diversification.

Portfolio management, in contrast, is a clearly identifiable dynamic capability because it is the process used to implement a firm's top-down strategy through projects (Morris and Jamieson, 2005; Morgan, Levitt and Malek, 2007). Portfolio management is about planning, mapping and scheduling a set of projects to achieve a firm's long-term strategic objectives (Loch and Kavadias, 2002 and 2011; Jonas, 2010; Killen, Jugdev, Drouin and Petit, 2012; Teller, Under, Kock, and Gemünden, 2012; Unger, Gemünden and Aubry, 2012; Unger, Kock, Gemünden and Jonas, 2012; Martinsuo, 2012).

In their classic article on management of development projects, Wheelwright and Clark (1992a \& 1992b) help to identify the role of portfolio management in balancing and sequencing innovative and routine projects. The 'aggregate project plan' is a portfolio management technique used for planning, allocating resources and sequencing projects carefully over time to achieve a firm's strategic goals. Projects are divided into different types ranging from 'derivative projects' that support incremental improvements and enhancements to existing products and processes (what we call routine projects) at one end of the spectrum to 'breakthrough projects' that create new and untried products and processes that are radically different to previous generations (innovative projects) at the other end. 'Platform projects' lie in the middle of spectrum and involve a mix unique/innovative and repetitive/routine elements. A typical product development cycle involves creating a balanced portfolio by allocating different combinations of resources and capabilities to different types of projects over time. The cycle begins when significant resources and experienced project leaders are assigned to work on the breakthrough project, followed by a select number of platform projects to establish each new generation of product or process, and ends with larger number of derivative projects where ongoing senior management involvement is minimal.

Our conceptualisation of dynamic and project capabilities provides a theoretical foundation, which is currently lacking in project management research, to overcome our 
current reliance on a practitioner-oriented view of portfolio management in project-based firms. Identifying portfolio management techniques as a dynamic capability for balancing project capabilities helps to identify how firms achieve the flexibility required to manage the trade-offs between innovation and routines, exploration and exploitation over time. Portfolio strategies also help us understand how dynamic capabilities support temporal sequencing of innovative and routine projects involved in the capability building process (Brady and Davies, 2004).

\subsubsection{Balancing project capabilities}

We can now illustrate with a variety of key contributions to the literature on projectbased organising, how dynamic capabilities are deployed by senior managers to manage the trade-offs, inconsistent alignments and potentially complementary relationship between innovative and routine project capabilities. How project capabilities are developed and applied, in turn, influences the composition, focus and application of dynamic capabilities in the future.

The challenge of simultaneously exploring and exploiting at the same time confronts organisations with a 'demanding balancing act' (Kanter, 1990). They have to exploit current investments and keep pace with routine projects they are already committed to in their home base, while at the same time launching innovative projects and exploring opportunities that will be of benefit in the future. Innovative projects differ in the extent to which they are physically and organisationally separate from the mainstream exploitative business. They may be set up as incubators for new ventures (Burgleman, 1984; Kanter, 1990), bootlegging projects undertaken unofficially (Augsdorfer, 1996), and separate project units to nurture creativity and new approaches, but sometimes, innovative projects are undertaken without leaving the home base.

To explore and exploit simultaneously requires that senior managers have to develop a clear vision, common identity and values that justify the ambidextrous design, avoiding the possibilities for conflict, disagreement and poor coordination among innovative and routine projects. The main challenge involved in promoting breakthrough innovation projects is 
internal (Shenhar and Dvir, 2007: 70). Organisations tend to allocate resources to less risky, routine projects that promote incremental innovation, and those that promise quick and reliable returns. Developing breakthrough innovation projects alongside well-established routine projects in the mainstream business "often hurts the novel project because powerful existing activities generate extensive sales, albeit in mature markets" (Shenhar and Dvir, 2007: 71). Because firms find it difficult to simultaneously explore and exploit, to succeed in breakthrough innovation they must spin out entirely separate project organisations - often called 'skunkworks' - focused on nurturing new customers and developing radical technology (Christensen, 1997). Dynamic capabilities refer to the senior management knowledge and activities required to promote and gain approval for breakthrough projects and overcome conflicts and any resistance to change from the organisation's established business units.

The distinction between innovative and routine projects is implicit in Shamsie et al's (2009) study of dynamic capabilities in a project-based industry - the Hollywood film studios between 1936 and 1965. Building on prior studies of project-based firms (Gann and Salter, 2000; Davies and Brady, 2000; Prencipe and Tell, 2001; Brady and Davies, 2004; Ethiraj et al, 2005), Shamsie et al (2009) argue that firms in their study were faced with periodic choices about whether to pursue a strategy of replication by exploiting their existing capabilities in various categories of routine projects in which they are currently successful. Alternatively, they could follow a renewal strategy by enhancing their capabilities in innovative project categories in which neither they nor their rivals have experienced success. Firms achieved successful renewal strategies based on the timing and pace of their efforts to explore and develop new capabilities more quickly than their rivals. Echoing research on ambidexterity, Shamsie et al (2009: 1450) conclude that firms deploying dynamic capabilities in project-based industries 'seek some level of balance between replication and renewal strategies'. Too much emphasis on one strategy over a period of time can erode a firm's ability to correct this imbalance. 


\subsubsection{Building project capabilities}

In addition to balancing, firms rely on dynamic capabilities to deal with the challenges involved in building project capabilities and managing the temporal sequencing involved in moving from exploration to exploitation.

Our own research on project capability building identifies how a firm's move into a new technology or market base involves a transition from exploratory to exploitative activities (Brady and Davies, 2004). The exploratory phase of learning begins when a firm first moves into new technology and market base and a new type of vanguard project is established at the frontier of an organisation's current project capabilities. A firm's existing project capabilities are mobilised to provide the vanguard team with the resources, expertise and freedom to experiment, innovate and move beyond established routines. But what goes on inside a vanguard project often quickly reveals the fragility of a firm's current project capabilities that, although well suited to a firm's existing base, are no longer appropriate when a firm engages in highly innovative projects in a rapidly changing and uncertain environment. New capabilities are formed to create novel product and service offerings, anticipate progress and capture the new thinking, ideas, competencies and structures required. One or several innovative projects may be required to support a firm's base-moving strategies to develop new technologies, create new markets or keep pace with a rapidly changing competitive environment (Davies and Hobday, 2005).

In the project capability building process, vanguard innovation projects are followed by phases of top-down, exploitative learning, when dynamic capabilities are relied upon to identify strategically valuable knowledge and to capture and transfer experience gained to subsequent projects and the organisation as a whole. Exploitative learning occurs in parallel with the project-level learning when strategic decisions are taken to develop the firm-wide project capabilities to support the new category of project and perform an increasingly predictable and standardized routines as the firm grows and matures in the new technology and market base. This cumulative knowledge and experience supports a firm's routine project capabilities by improving processes and extending the lives of existing products. 
The idea that vanguards generate different trajectories or epochs of project capability building can be addressed by zooming out to study the evolution of a firm over an extended period of time. Söderlund and Tell (2009) recognize that project-based firms rely on dynamic capabilities to explore new possibilities and exploit what is already known. In an historical study of Asea/ABB, they show that the development of the firm's project capabilities was led by a series of vanguard projects and associated with four 'project epochs' during the second half of the $20^{\text {th }}$ century. A key challenge facing Asea/ABB was the need to reconfigure the firm's project capabilities during each disruptive shift between epochs, when a long period of exploitation was punctuated by the establishment of a new vanguard project, a renewed focus on the exploration of new possibilities and the beginning of a new epoch of project capability building. Too much reliance on portfolio techniques to manage a set of projects may encourage path dependence in dynamic capabilities (Killen, Hunt and Kleinschmidt, 2008) leading to inertia and core rigidities, requiring new vanguard projects to break with the past and initiate a new epoch of project capability building.

\section{New directions for research}

Research highlights how dynamic capabilities help firms achieve competitive advantage by modifying or creating new lower-level operational capabilities and routines to address changing environmental conditions (Nelson and Winter, 1982; Chandler, 1992; Teece et al, 1997; Zollo and Winter, 2002; Helfat and Peteraf, 2003; Teece, 2007 \& 2010). Eisenhardt and Martin (2000) identify different categories of dynamic capabilities to address moderately-dynamic and volatile conditions. Others have emphasised the importance of dynamic capabilities (and metaroutines) in helping senior managers know when to exploit current operational capabilities when conditions are stable and predictable and when to modify them to keep pace with a changing environment (Knott, 2001; Tushman and O'Reilly, 2008). We build on and contribute to this growing body of literature by unravelling how a firm's project capabilities, innovative and routine, can be deployed to address a variety of contingent conditions. 
Our new conceptualisation of project capabilities provides rich and fruitful opportunities for future research. Although some scholars have used this concept in previous empirical studies of project organisations, this article provides a foundation for future research using project capabilities, based on three main contributions. First, by reviewing prior research on dynamic capabilities and identifying the role of ambidexterity in achieving a close fit with contingent conditions, we define innovative and routine categories of project capabilities to address exploratory and exploitative conditions found within and between projects. Second, we develop a clear distinction between project and dynamic capabilities. Project capabilities refer to the management knowledge, structures and tasks required at the operational level to deal with different types of individual projects (project management for innovative and routine projects) or interrelated sets of projects (program management), whereas dynamic capabilities are required to select, sequence and manage a set of projects over time to achieve a firm's longer term strategic objectives (portfolio management). Third, this article makes clear that in previous studies researchers have neglected the role of project (and operational) capabilities in providing strategic direction, insights and new situationspecific knowledge for the future development and deployment of dynamic capabilities. To remedy this situation, we developed a model showing the multiple, reciprocal, iterative and fluid links between project and dynamic capabilities.

Taken together, these three contributions represent a departure from the prevailing view of project capabilities. Whereas prior research often confuses project and dynamic capabilities, we define the links between the two sets of capabilities and identify the contingent dimensions of project capabilities. Through the definition, dimensions and model of project capabilities put forward in this article, we can identify promising avenues for future research.

\subsection{The fluidity and fragility of project capabilities}

Further research needs to consider how project capabilities evolve, grow and ultimately decline during a life cycle from birth to maturity (Helfat and Peteraf, 2003). It needs to examine the role played by vanguard projects as the launch pad for the creation of a 
new project capability during the founding stages of the life cycle. Vanguard projects are where new project capabilities are born and nurtured, and where simple rules, situationspecific knowledge and real-time experiential learning are created to deal with a novel, fluid and high-velocity environment (Eisenhardt and Martin, 2000). When a project is radically new to the people involved, there is a significant amount of exploration required to learn the new tasks, consider innovative alternatives and a high probability of unpredicted discoveries during the execution of the project (Engwall, 2003). However, radically new vanguard projects may also challenge existing capabilities, knowledge base and structures of the parent organisation. Traditional project capabilities that made projects successful in the past may become core rigidities (Leonard-Barton, 1992), hindering rather than supporting the new project.

While a central objective of a newly-formed vanguard project is the development of some new project capabilities to achieve the project's goals, the team is not devoid of a capability pre-history. Members of the founding team may have a history of working together on previous projects and bring their previous experience, skills and knowledge, social ties and cognitive models. Research on the nature of capability development in vanguard projects cannot be understood without taking into account the history of the parent organisation (Söderlund and Tell, 2009). Vanguard projects involve a combination of novel ideas, new roles and unique elements as well as existing routines, repetition of previous procedures and well-established approaches.

Since the capability is new to the organization in the founding stage of the life cycle, the project capability may evolve and change with little or no intervention of any dynamic capabilities. Founding members of the vanguard projects have to explore alternatives for capability development, conduct on-line and off-line trials of alternatives (Gavetti and Levinthal, 2000) and build on their experience over time during later stages of the capability life cycle. The early feedback and learning gained during the performance of a vanguard project provides direction and strategic focus for the deployment of dynamic capabilities during subsequent stages of development. 
The simple routines required to address the exploratory conditions in vanguard projects gradually stabilize during later stages in the capability life cycle time as conditions become more familiar, predictable and well-understood, eventually resembling the standardised operating procedures. The exploitation of existing project routines provide predictability in stable and moderately-dynamic environments. However, there are less likely to furnish unpredictable discoveries and new procedures due to economies of repetition (Davies and Brady, 2000; Engwall, 2003).

Well-established, predictable and reliable project capabilities can easily become unstable and fragile when conditions change. Further research is required to understand how firms such as $\mathrm{ABB} / \mathrm{Asea}, \mathrm{IBM}$ and Ericsson use dynamic capabilities to manage the critically important transition from one project epoch to the next, focusing how they create time for reflection to assess the adequacy of their existing project capabilities and how they actually modify or abandon them as the firm branches out in new directions (Söderlund and Tell, 2009).

\subsection{Capabilities within complex projects}

We have distinguished between projects that are unique, novel and innovative and those that are repetitive, simple and routine (Eisenhardt and Tabrizi, 1995; Loch et al, 2006; Shenhar and Dvir, 2007). While helpful in understanding how firms manage distinct types of projects, it is important to recognise that large and complex projects have to perform regular, repetitive and predictable project routines when conditions are stable and predictable, whilst at the same time promoting innovation to deal with unexpected, rapidly changing and novel situations (Brady, Davies and Nightingale, 2012). As Engwall (2003) points out, complex projects are really a 'conglomerate' of unique tasks and new procedures applied for the first time and highly standardized and repetitive tasks that have been exploited on previous projects. Although this is partially addressed in prior research (Stinchcombe and Heimer, 1985; Davies, Gann and Douglas, 2009), we need to further expand our understanding of the range of contingent conditions found within complex projects. 
Projects are a form of temporary organisation ranging from multiple projects that are fully embedded in the firm to complex standalone projects involving multiple participating organisations (Schwab and Miner, 2008; Jones and Lichtenstein, 2008). Prior research largely focuses on how firms develop dynamic capabilities to manage a portfolio of embedded projects (Gann and Salter, 2000; Ethiraj, Kale, Krishnan and Singh, 2005; Söderlund and Tell, 2009; Shamsie, Martin and Miller, 2009; Cattini, Ferriani, Frederiksen and Täube, 2011). With a few recent exceptions (Davies, Dodgson and Gann, 2015; Grabher and Thiel, 2015), research rarely studies how dynamic or project capabilities are deployed to manage largescale, complex and uncertain projects, such as weapons systems, oil and gas platforms, rail transportation links, nuclear power plants, energy networks and airports (Morris and Hough, 1987; Miller and Lessard, 2000; Morris, 2013; Flyvbjerg, Bruzelius, and Rothengatter, 2003).

The challenge of balancing innovation and routine action is recognised in in-depth case studies of complex projects containing a variety of predictable and highly uncertain conditions (Sayles and Chandler, 1971; Sapolsky, 1972; Davies et al, 2009; Lenfle and Loch, 2010; Davies and MacKenzie, 2014; Brady and Davies, 2014). These projects have perform a planned schedule of standardised project routines to deal with predictable and known risks, whilst at the same time having the flexibility to adjust plans and modify routines when conditions change. In his study of the Polaris missile system, Sapolsky (1972: 250) identified the need for 'disciplined flexibility' in complex projects to ensure that certain project routines and processes have to remain firmly fixed, whilst others had to be kept open to address unexpected situations. In their study of the Heathrow Terminal 5 project, Davies et al (2015) suggest that British Airports Authority (BAA) developed an entirely new project delivery model to support disciplined flexibility which was embodied in a dynamic capability called the 'T5 Agreement'. Similarly, the Change Control Board was used by senior managers on the London 2012 Olympics project to strike a balance between the need for stability and change (Davies and Mackenzie, 2014).

Future research needs to explore how organisations - clients, owners and contractors - develop dynamic capabilities to balance routine and innovative tasks in complex projects. In 
their study of North Sea oil and gas projects, Stinchcombe and Heimer (1985) emphasized that a collection of project routines are required to address predictable conditions and known risks, whilst innovation is needed to deal with unexpected and rapidly changing conditions. This suggests that firms like Shell, BP and Chevron, benefit from developing the dynamic capabilities and ambidexterity required to manage a number of ongoing complex projects. As shown in Figure 2, the need for ambidexterity is apparent in Lenfle and Loch's (2010) argument that complex projects can be broken down into pieces of uncertainty, with distinct structures and processes established to deal with foreseeable (standardised project management planning and execution routines) and unforeseeable uncertainty (parallel trials and iterative learning to support innovation). Further research is needed to understand how dynamic and project capabilities connect with each other to deal with the challenges involved in managing the variety of conditions found within complex projects.

insert Figure 2

\subsection{The paradox of project capabilities}

We recognise that the idea of project capabilities presents a paradox. Capabilities are considered to be enduring, whereas projects are ephemeral. We have proposed ways out of the paradox of project capabilities by showing that a permanent organisation, usually a firm, develops the capabilities (dynamic and project) to manage multiple projects. But many oneoff projects are executed by large standalone temporary organisations. Unless they are embedded in a permanent organisation, members of a standalone project cannot rely on a

firm's existing experience, capabilities and memory of past projects. However, research suggests that project capabilities may be assembled on a temporary basis when a project organisation is embedded in a wider inter-organisational network (Jones and Lichtenstein, 2008) or project ecology (Grabher, 2002). Learning and capability building is possible in standalone inter-organisational projects if participants form a network of enduring relationships established by working together on previous projects. When collaboration is 
repeated across projects, the trust established among the parties involved can form a repository of project capabilities that can be retrieved when participants work together on subsequent projects (Sydow et al, 2004; Manning and Sydow, 2011).

There is a need for research to study how dynamic and project capabilities are assembled by owners and operators to manage large, one-off complex projects (Winch, 2014), such as major infrastructure, technological systems and large-engineering projects (Hughes, 1998; Miller and Lessard, 2000; Flyvbjerg et al, 2003). Complex projects are often structured as programs and placed under the control of an 'umbrella organisation' to coordinate multiple contractors and deal with financial, logistical, political and legal issues (Shenhar and Dvir, 2007: 105). There are two contrasting types of client-based owner and operator organisations established to manage complex projects (Brady and Davies, 2014; Davies et al, 2015).

First, a 'permanent client' organization under various forms of public and private ownership, such as BP, Shell, BAA, Network Rail and the London Underground, are responsible for executing many smaller capital projects and a few less frequent complex projects. Responsible for delivering a number of complex projects episodically over many years - as in the case of BAA (now Ferrovial) at Heathrow airport - permanent clients have an opportunity and incentive to develop the capabilities required to manage each project and utilize the learning gained to improve the delivery of subsequent projects (Davies, Gann and Douglas, 2009).

Second, a 'temporary client' organization, typically under public ownership, is often established to execute a single large complex project, such as the Channel Tunnel Rail Link (High-Speed 1), London 2012 Olympics and Crossrail suburban railway system (Davies, MacAulay, Debarro, and Thurston, 2014). In these projects, a separate operating company (e.g. Crossrail Limited) is created for the duration of a complex project. Further research is required to understand how different combinations of dynamic and project capabilities are developed from scratch, in a limited period of time, and are dissolved on completion of such projects. Whereas BAA's dynamic capability was developed for T5 and intended for 
application on future complex projects (e.g. Terminal 2), research needs to explore how and why temporary clients build and apply dynamic and project capabilities for one-off complex projects with little or no possibility of reusing these capabilities on future projects.

Temporary clients that make infrequent or one-off investments in complex projects face greater difficulties in assembling the dynamic and project capabilities required to manage one-off projects. More research is needed to understand how a temporary client can assume responsibility for 'systems integration' by developing the capabilities in-house to coordinate the large network of suppliers involved in the design and integration of multiple systems, or by appointing a prime contractor to assume responsibility for this role, or by establishing a temporary joint-venture organisation to assist with this process (Davies and Mackenzie, 2014). The use of 'delivery partner' organisations for the London 2012 Olympics and Crossrail projects are interesting examples of temporary joint-venture organisations established to assemble the project capabilities required to manage each program and the interfaces between individual projects on behalf of the client or owner. In the case of the Olympics, the client - the Olympic Delivery Authority - used competitive tendering to select CLM as its delivery partner, combining the distinctive capabilities of three different firms: CH2M Hill, Laing O’Rourke and Mace.

Although recent research is considering how dynamic or project capabilities are mobilised in complex projects, future research needs to address how these two set of work together. Davies et al (2015) explain how BAA built, codified and mobilised a set of 'dynamic capabilities' embodied in the T5 Agreement and associated strategic practices (e.g. collaborative integrated project teams and contractual incentives supporting innovative problem solving) to execute the project. Grabher and Thiel (2015) explain that due to their inherently temporary nature a one-off complex project like the London 2012 Olympics cannot rely on a permanent parent organization to provide the requisite 'project capabilities'. Instead the client has to mobilise the specialised knowledge and project capabilities embedded in a network of firms and individual project professionals that bring their experience from previous projects. This study underlines the importance of undertaking further research on the 
wider ecosystem of project capabilities distributed among a community of firms and professionals that have worked on previous projects and can be assembled, dismantled and reassembled on a temporary basis to support complex projects undertaken episodically over many years.

\section{Conclusion}

This article provides a new conceptualisation of project capabilities to address advances in theory and new empirical research. We hope that the article encourages future research on the ambidextrous dimensions of project capabilities, the links between this construct and dynamic capabilities, and its application to new domains of project-based organising (Winch, 2014). It is reassuring that other researchers have recognised the importance of project capabilities, and we hope that future uses of the concept will show greater recognition of its innovative and routine, exploratory and exploitative dimensions.

We started the article by acknowledging how, throughout his career, Peter Morris has emphasised that successful projects depend on the specialised knowledge, skills and capabilities of organisations, teams and individuals. In his recent work, Morris (2013) devotes a whole chapter to the individual skills, competencies and knowledge of people at the operational and strategic levels of projects. Whereas our original definition of project capabilities was confined to knowledge developed and mobilised at the organisational level, it is important to recognise that recent research (Grabher and Thiel, 2015) is now exploring how specialised project capabilities embedded in individual experienced individuals and distributed across the wider ecosystem of project organisations are so vital to the successful set up and execution of projects. Peter was on to something important, as usual.

\section{References}

Adler, P.S., Goldoftas, B. and Levine, D.I (1999). 'Flexibility versus efficiency? A case study of model changeovers in the Toyota production system'. Organization Science 10(1) 43-68.

Amburgey, T.L., D. Kelly, W.P Barnett. (1993). 'Resetting the clock: the dynamics of organizational change and failure'. Administrative Science Quarterly 38 51-73. 
Amsden, A. and Hikino, T. (1994). Project execution capability, organizational know-how, and conglomerate corporate growth in late industrialization Cambridge, MA : MIT Japan Program, Massachusetts Institute of Technology.

Augsdorfer, P. (1996). Forbidden Fruits: An Analysis of Bootlegging, Uncertainty and Learning in Corporate R\&D, Aldershot: Averbury.

Barney, J. (1991). 'Firm resources and sustained competitive advantage', Journal of Management, Vol. 17. No 1, 99-120.

Brady, T. and Davies, A. (2004). 'Building project capabilities: from exploratory to exploitative learning', Organizational Studies, 26 (9), 1601-1621.

Brady, T. and Davies, A. (2014). 'Managing structural and dynamic complexity: a tale of two projects', Project Management Journal, 45(2): 21-38.

Brady, T., Davies, A. and Nightingale, P. (2012). Dealing with uncertainty in complex projects: Revisiting Klein and Meckling. International Journal of Managing Projects in Business, 5(4): 661-679.

Burgleman, R.A. (1984). 'Managing the internal corporate venturing process', Sloan Management Review, Winter 1984, 33-48.

Burns, T., and Stalker, G.M. (1961). The management of innovation. Oxford: Oxford University Press.

Cattani, G., Ferriani, S., Frederiksen, L. and Täube, F. (2011), 'Project-based organizing and strategic management: a long-term research agenda on temporary organizational forms', Advances in Strategic Management, 28, 3-26.

Chandler, A.D. (1990). Scale and scope: the dynamics of industrial capitalism, Cambridge: Belknap, Harvard University Press.

Chandler, A.D. (1992). 'Organizational capabilities and the economic history of industrial enterprise', Journal of Economic Perspectives, 6(3): 79-100.

Christensen, C.M. (1997). The innovator's dilemma: when new technologies cause great firms to fail. Boston, Mass: Harvard Business School Press.

Collis, D.J. (1994). 'Research note: how valuable are organizational capabilities'. Strategic Management Journal 15 143-152.

Coriat, B. (2000). 'The 'Abominable Ohno Production System'. Competences, monitoring, and routines in Japanese production systems', G. Dosi, R.R. Nelson, S.G. Winter (eds.). 2000. The nature and dynamics of organizational capabilities, Oxford: Oxford University Press, 213-240.

Cusumano, M.A. and Nobeoka, K. (1998), Thinking Beyond Lean: How Multi-project Management is Transforming Product Development at Toyota and Other Companies, New York, NY, The Free Press,.

Cyert, R.M. and March, J.G. (1963). A behavioural theory of the firm. Englewood, Cliffs, New Jersey, Prentice-Hall. 
Daneels, E. (2008). Organizational antecedents of second-order competences'. Strategic Management Journal 29 519-543.

Daneels, E. (2010). 'Trying to become a different type of company: dynamic capability at Smith Corona'. Strategic Management Journal 32 1-31.

Davies, A. and Brady, T. (2000), 'Organisational Capabilities and Learning in Complex Product Systems: Towards Repeatable Solutions’, Research Policy, 29, 931-953.

Davies, A. and Hobday, M. (2005), The Business of Projects: Managing Innovation in Complex Products and Systems, Cambridge University Press, Cambridge.

Davies, A., Gann, D. and Douglas, T. (2009), 'Innovation in Megaprojects: Systems Integration at London Heathrow Terminal 5', California Management Review, 51(2), 101125.

Davies, A., Dodgson, M. and Gann, D. (forthcoming 2015). 'Dynamic capabilities for a complex project: innovation happen in a megaproject: The case of London Heathrow Terminal 5', Special Issue: Innovation and Project Management: Bridging Contemporary Trends in Theory and Practice, Project Management Journal.

Davies, A. and Mackenzie, I. (2014). 'Project complexity and systems integration: constructing the London 2012 Olympics and Paralympics Games', International Journal of Project Management, 32: 773-790.

Davies, A. and Frederiksen, L. (2010) 'Project modes of innovation: the world after Woodward', Special Issue: Technology and organization: essays in honour of Joan Woodward, Research in the Sociology of Organizations, 29, 177-215.

De Meyer, A., C.H. Loch, and M.T. Pich, (2002). 'Managing project uncertainty', Sloan Management Review, 43(2) 6-67.

Di Stefano, G., Peteraf, M. and Verona, G. (2014). 'The organizational drivetrain: a road to integration of dynamic capabilities research, forthcoming, Academy of Management Perspectives.

Easterby-Smith, M., Lyles, M.A. and Peteraf, M.A. (2009). 'Dynamic capabilities: current debates and future directions', British Journal of Management, 20(1): 1-8.

Eisenhardt, K. M. and Martin, J.A. (2000). 'Dynamic capabilities: what are they?'. Strategic Management Journal 21 1105-1121.

Eisenhardt, KM, Furr, NR, Bingham, CB. 2010. Microfoundations of performance: balancing efficiency and flexibility in dynamic environments. Organization Science 21(6): 1263-1273

Eisenhardt, K. M. and Sull, D.N. (2000). 'Strategy as simple rules'. Harvard Business Review January 106-116.

Eisenhardt, K. M. And Tabrizi, B.N. (1995). 'Accelerating adaptive processes: product innovation in the global computer industry'. Administrative Science Quarterly 40 84-110.

Engwall, M. (2003): 'No project is an island: linking projects to history and context', Research Policy, Vol. 32, 798-808. 
Ethiraj, S.K, Kale, P., Krishnan, M.S. and Singh, J.V. (2005. 'Where do capabilities come from and how do they matter? A study in the software services industry'. Strategic Management Journal 26 25-45.

Frederiksen, L. and Davies, A. (2008) 'Vanguards and ventures: projects as vehicles for corporate entrepreneurship', International Journal of Project Management, 26, 487-496.

Flyvbjerg, B, Bruzelius, N, Rothengatter, W. 2003. Megaprojects and risk: an anatomy of ambition. Cambridge University Press: Cambridge.

Gann, D.M. and A. Salter 2000 'Innovation in project-based, service-enhanced firms: the construction of complex products and systems', Research Policy 29: 955-972.

Gavetti, G., D. Levinthal. (2000). 'Looking forward and looking backward: Cognitive and experiential search'. Administrative Science Quarterly 45 113-137.

Hackman, J.R., R.Wageman. (1995). 'Total quality management: empirical, conceptual, and practical issues'. Administrative Science Quarterly 40 309-342.

Helfat, C.E. and Peteraf, M.A (2003). 'The dynamic resource-based view: capability lifecycles'. Strategic Management Journal 24 997-1010.

Helfat, C.E. and Winter, S.G. (2011). 'Untangling dynamic and operational capabilities: strategy for a (n)ever-changing world'. Strategic Management Journal 32 1243-1250.

Hobday, M. (1998). 'Product complexity, innovation and industrial organisation', Research Policy, 26: 689-710.

Hobday, M. (2000). 'The project-based organization: an ideal form for management of complex products and systems'. Research Policy, 29: 871-893.

Hughes, T.P. (1998). Rescuing Prometheus, New York: Pantheon Books.

Jonas, D. (2010). 'Empowering project portfolio managers: How management involvement impacts project portfolio management performance', International Journal of Project Management, 28 818-831

Jones, C. and Lichtenstein, B. (2008). 'Temporary inter-organizational projects: How temporal and social embeddedness enhance coordination and manage uncertainty'. In S. Cropper, M. Ebers, C. Huxman and P. Smith Ring (Eds.). The Oxford Handbook of InterOrganizational Relations (pp. 231-255), Oxford, UK: Oxford University Press.

Kanter, R. M. (1990). When elephants learn to dance: mastering the challenges of strategy, management, and careers in the 1990s. London: Unwin Paperbacks.

Killen, C., Drouin, N., Jugdev, K. and Petit, Y. (2012). 'Advancing Project and Portfolio Management Research with Strategic Management Theories on Resources, Competencies, and Capabilities', International Journal of Project Management, vol. 30(5), 525.

Killen, C., Hunt, R. and Kleinschmidt, E. (2008) Project portfolio management for product innovation, International Journal of Quality \& Reliability Management, 25(1), 24 - 38

King, A.A., C.L. Tucci. (2002). 'Incumbent entry into new market niches: the role of experience and managerial choice in the creation of dynamic capabilities'. Management Science 48(2) 171-186. 
Klein, B. and Meckling, W. (1958). 'Application of operations research to development decisions', Operations Research, Vol. 6, 352-363.

Knott, A.M. (2001). 'The dynamic value of hierarchy'. Management Science 47(3) 430-448.

Lenfle, S. (2008). 'Exploration and project management', International Journal of Project Management, 26: 469-478.

Lenfle, S. and Loch, C. (2010). 'Lost roots: How project management came to emphasize control over flexibility and novelty', Californian Management Review, Fall, 53(1): 32-55.

Leonard-Barton, D. (1992). 'Core capabilities and core rigidities: A paradox in managing new product development'. Strategic Management Journal 13: 111-125.

Loch, C., De Meyer, A., Pich, M. 2006. Managing the unknown: a new approach to managing high uncertainty and risk in projects. John Wiley and Sons: New Jersey.

Loch, C. and Kavadias, S. (2002). 'Dynamic portfolio selection of NPD programs using marginal returns', Management Science, 48(10), 1227-1241.

Loch, C. and Kavadias, S. (2011). 'Implementing strategy through projects', pp224-251 in Morris et al, (2011). The Oxford handbook of project management, Oxford: Oxford University Press.

Lundin, R. A. and A. Söderholm (1995) A theory of the temporary organization. Scandinavian Journal of Management, 11(4): 437-455.

Lundin, R. A., Arvidsson, N., Brady, T., Ekstedt, E., Midler, C., and Sydow, J. (forthcoming 2015) Managing and Working in Project Society:Institutional Challenges of Temporary Organizations, Cambridge, Cambridge University Press

Manning, S. and Sydow, J. (2011) Projects, paths, practices: Sustaining and leveraging project-based relationships. Industrial \& Corporate Change, 20 (5): 1369-1402.

March, J.G. (1991). 'Exploration and exploitation in organizational learning', Organization Science, 2: 71-87.

Martinsuo, M. (2012). Project portfolio management in practice and in context. International Journal of Project Management, 31(6), 794-803.

Miller, R. and Lessard, D.R. (2000). The Strategic Management of Large Engineering Projects: Shaping Instutions, Risks, and Governance, Cambridge, Mass: The MIT Press.

Morgan, M., Levitt, R.E. and Malke, W. (2007). Executing your strategy: how to break it down and get it done, Boston: Harvard Business School Press.

Morris, P. W. G. and Hough, G.H. (1987). The anatomy of major projects. Chichester: John Wiley \& Sons.

Morris, P. W. G. (1994). The management of projects. London: Thomas Telford.

Morris, P. W. G. (2013). Reconstructing project management. Chichester: John Wiley \& Sons. 
Morris, P.W.G., Pinto J.K. and Söderlund, J.(eds) (2011). The Oxford Handbook of Project Management, Oxford: Oxford University Press.

Morris, P.W.G. and Jamieson, A. (2005) 'Moving corporate strategy to project strategy', Project Management Journal, December: 5-18.

Nelson, R.N. and Winter, S.G. (1982). An evolutionary theory of economic change.

Cambridge, Mass, The Belknap Press of Harvard University Press.

Nightingale, P., Baden-Fuller, C, and Hopkins, M. 2011 Projects, Project Capabilities and Project Organisations In: Cattani, Gino, Ferriani, Simone, Frederiksen, Lars and Taube, Florian (eds.) Advances in Strategic Management. Emerald Group Publishing Limited, pp. 215-234

Nightingale, P. and Brady, T. (2011). 'Projects, paradigms and predictability, in Project-based organizing and strategic management', Advances in Strategic Management, 28: 83-112.

O'Reilly, C.A., and Tushman, M.L. (2004). 'The ambidextrous organization', Harvard Business Review, April: 74-833.

O'Reilly, C.A., and Tushman, M.L. (2008). 'Ambidexterity as a dynamic capability: resolving the innovator's dilemma', Research in Organizational Behavior, 28: 185-206.

Pellegrinelli, S., Partington, D. and Geraldi, J.G. (2011). 'Program management: an emerging opportunity for research and scholarship', pp252-272 in Morris et al, (2011). The Oxford handbook of project management, Oxford: Oxford University Press.

Pellegrinelli, S., Murray-Webster, R. and Turner, N. (2014). 'Facilitating organizational ambidexterity through the complementary use of projects and programs', International Journal of Project Management, forthcoming.

Penrose, E. (1959). The theory of the growth of the firm. Oxford: Oxford University Press.

Peteraf, M., Di Stefano, G. and Verona, G. (2013). 'The elephant in the room of dynamic capabilities: bringing two diverging conversations together', Strategic Management Journal, 34: 1389-1410.

Pich, M.T., Loch, C.H., and De Meyer, A. (2002). 'On uncertainty, ambiguity and complexity in project management', Management Science, 48 (8): 1008-23.

Prencipe, A. and Tell, F. (2001). 'Inter-project learning: processes and outcomes of knowledge codification in project-based firms', Research Policy, 30: 1373-1394.

Richardson, G.B. (1972). 'The Organisation of Industry', Economic Journal, Vol. 82, 883896.

Sapolsky, H. M. (1972). The Polaris System Development: Bureaucratic and Programmatic Success in Government, Cambridge, Mass: Harvard University Press.

Sayles, L. and Chandler, M.K. (1971). Managing Large Systems, The Free Press, New York.

Shamshie, J., Marin, X. and Miller, D. (2009). 'In with the old, in with the new: capabilities, strategies, and performance among the Hollywood Studios', Strategic Management Journal, 30: $1440-1452$. 
Shenhar, A. J., and Dvir, D. (2007). Reinventing project management: the diamond approach to successful growth and innovation. Boston, Mass: Harvard Business School Press.

Söderlund, J. (2005). 'Developing project competence: empirical regularities in competitive project operations', International Journal of Innovation Management, 9(4): 451-480.

Söderlund, J. and Tell, F. (2009). 'The P-form organization and the dynamics of project competence: project epochs in Asea/ABB, 1950-2000', International Journal of Project Management, 27, 101-112.

Stinchcombe, A. L., and Heimer, C. A. (1985). Organization theory and project management: administering uncertainty in Norwegian offshore oil. Oslo: Norwegian University Press and Oxford University Press.

Sydow, J., Lindkvist, L. and DeFillippi, R. (2004) Project-based organizations, embeddedness and repositories of knowledge - Editoral. Organization Studies, 25(9): 1475-1489.

Teece, D., G. Pisano. (1994). 'The dynamic capabilities of firms: an introduction'. Industrial and Corporate Change 3(3) 537-556.

Teece, D., G. Pisano and A. Shuen. (1997). 'The dynamic capabilities and strategic management'. Strategic Management Journal 18(7) 509-533.

Teece, D. (2007). 'Explicating dynamic capabilities: that nature and microfoundations of (sustainable) enterprise performance'. Strategic Management Journal 28(13) 1319-1350.

Teece, D. (2010). 'Alfred Chandler and 'capabilities' theories of strategy and management', Industrial and Corporate Change, 297-316.

Teller, J., Under, B., Kock, A.and Gemünden, H. (2012). 'Formalization of project portfolio management: The moderating role of project portfolio complexity'. International Journal of Project Management, 30(5):596-607.

Tripsas, M., and G. Gavetti, (2000). Capabilities, cognition, and inertia: evidence from digital imaging. Strategic Management Journal, 21: 1147-1161.

Turner, N. Maylor, H. and Swart, J. (2014). 'Ambidexterity in projects: an intellectual capital perspective', International Journal of Project Management, forthcoming.

Turner, N., Maylor, H., Lee-Kelley, L., Brady, T., Kutsch, E. and Carver, S. (2014).

'Ambidexterity and knowledge strategy in major projects: a framework and illustrative case study', Project Management Journal, 45(5), forthcoming.

Tushman, M.L. and O'Reilly, C.A. (1996). 'The ambidextrous organization: managing evolutionary and revolutionary change'. California Management Review, 38: 1-23.

Tushman, M.L. \& O'Reilly, C. (1997). Winning through innovation. Boston, MA: Harvard Business School Press.

Unger, B. N., Gemünden, H. G., Aubry, M. (2012): The Three Roles of a Project Portfolio Management Office: Their Impact on Portfolio Management Execution and Success. In: International Journal of Project Management, 30(5): 608-620

Unger, B. N.; Kock, A.; Gemünden, H. G.; Jonas, D. (2012): Enforcing Strategic Fit of Project Portfolios by Project Termination: An Empirical Study on Senior Management 
Involvement., International Journal of Project Management, 30(6): 675-685

Utterback, J.M. (1994). Mastering the dynamics of innovation: how companies can seize opportunities in the face of technological change. Mass: Harvard Business School Press.

Wezel, F..C., G. Cattani, J.M. Pennings. (2006). 'Competitive implications of interfirm mobility’. Organization Science 17(6) 691-709.

Wheelwright, S. C., and Clark, K. B. (1992a). 'Creating project plans to focus product Development', Harvard Business Review, 5(March-April), 70-82.

Wheelwright, S. and Clark, K.B. (1992b), Revolutionizing Product Development, The Free Press, New York, NY.

Whitley, R. (2006). 'Project-based firms: New organizational form or variations on a theme?', Industrial and Corporate Change, 15(1), 77-99.

Winch, G. (2014). 'Three domains of project organizing', International Journal of Project Management, 32: 721-731.

Winter, S.G. (1995). 'Four Rs of profitability: rents, resources, routines, and replication', C. Montgomery (Ed.), Resource-based and evolutionary theories of the firm. Boston, MA:

Kluwer Academic Publishers.

Winter, S.G. (2003). 'Understanding dynamic capabilities'. Strategic Management Journal 49(8): 1402-1406.

Winter, S.G. (2012). 'Capabilities: their origins and ancestry', Journal of Management Studies 24: 991-995.

Zollo, M., S.G. Winter. (2002). 'Deliberate learning and the evolution of dynamic capabilities'. Organization Science 13(3) 339-351. 